九州大学学術情報リポジトリ

Kyushu University Institutional Repository

\title{
Investigation of Direct and Indirect Evaporative Cooling Options for Greenhouse Air Conditioning in Multan (Pakistan)
}

Noor, Shazia

Department of Agricultural Engineering, Bahauddin Zakariya University

Ashraf, Hadeed

Department of Agricultural Engineering, Bahauddin Zakariya University

Sultan, Muhammad

Department of Agricultural Engineering, Bahauddin Zakariya University

Miyazaki, Takahiko

Faculty of Engineering Sciences, Kyushu University

他

https://doi.org/10.5109/4102474

出版情報: Proceedings of International Exchange and Innovation Conference on Engineering \& Sciences (IEICES). 6, pp.110-115, 2020-10-22. Interdisciplinary Graduate School of Engineering Sciences, Kyushu University

バージョン：

権利関係 : 


\title{
Investigation of Direct and Indirect Evaporative Cooling Options for Greenhouse Air Conditioning in Multan (Pakistan)
}

\author{
Shazia Noor ${ }^{1,2}$, Hadeed Ashraf ${ }^{1}$, Muhammad Sultan ${ }^{1, *}$, Takahiko Miyazaki ${ }^{3}$, Muhammad H. Mahmood ${ }^{1}$, Zahid M. \\ $\mathrm{Khan}^{1}$ \\ ${ }^{1}$ Department of Agricultural Engineering, Bahauddin Zakariya University, Multan 60800, Pakistan \\ ${ }^{2}$ Department of Mechanical Engineering, Bahauddin Zakariya University, Multan 60800, Pakistan \\ ${ }^{3}$ Faculty of Engineering Sciences, Kyushu University, Kasuga-koen 6-1, Kasuga-shi, Fukuoka 816-8580, Japan. \\ Corresponding author email: muhammadsultan@bzu.edu.pk
}

\begin{abstract}
Extreme sensible and latent load inside a greenhouse is a challenge faced in greenhouse farming which ultimately affects the crop yield and adds into food insecurity. In this regard, proper ventilation and air-conditioning is required to control the atmosphere inside the greenhouse. In this study, three experimental evaporative cooling (EC) (i.e. direct (DEC), indirect (IEC), and Maisotsenko cycle (MEC)) systems were thermodynamically analyzed for potential application of greenhouse air-conditioning for the climatic conditions of Multan. According to American Society of Agricultural Engineers (ASAE), temperature inside a greenhouse should be $30-32^{\circ} \mathrm{C}$. From a year-long experiment, results of $15^{\text {th }}$ May showed that DEC, MEC, and IEC resulted in process air of $27^{\circ} \mathrm{C}, 20^{\circ} \mathrm{C}$, and $31.4^{\circ} \mathrm{C}$ at $40^{\circ} \mathrm{C}$ ambient temperature, respectively. The DEC and MEC systems performed better as compared to the IEC system. The results indicate that the DEC and MEC systems perform optimally for greenhouse air-conditioning according to ASAE standards.
\end{abstract}

Keywords: Evaporative cooling, greenhouse, air conditioning, Pakistan

\section{INTRODUCTION}

Greenhouse agriculture technique is a vital need of the current century due to rising temperature and global warming. Food scarcity is one of the main issues being faced by the current generation in some portions of the world and this issue might explode to become a global threat in the coming decades if not properly dealt with. Owing to the global warming, rising temperature is causing the spoilage of cultivated crops in cropping seasons resulting in a below average yield per crop. In this regard, farmers are striving to meet their and general population's food needs. Greenhouse farming is an eyecatching agriculture technique in the farming community. Year-round cropping can be instigated using this technique. Optimum temperature and humidity control can be provided to the crop in greenhouses. Major issue being faced by the greenhouse farming community is overheating of atmosphere inside the greenhouse during high summers. Overheating causes spoilage and abnormal growth in plants. To solve this issue, natural and forced ventilation as well as temperature and humidity control units are used. Conventional vapor compression direct expansion (DX) systems are used as common practice to produce forced ventilation of the environment inside the greenhouse. These DX systems have been proved to be costly, and unfriendly to the environment.

Evaporative cooling (EC) is an alternative, green and low-cost air conditioning system for human as well as non-human applications as well. EC systems can be categorized into direct evaporative cooling (DEC), indirect evaporative cooling (IEC) and an advanced form of indirect evaporative cooling called Maisotsenko-cycle evaporative cooling (MEC). Evaporative cooling produces cooling effect using a draft of air flow passing over and/or through water. Water vapors detached from surface of water are added into the air creating a water vapor deficit. Owing to this "evaporation" process, a cooling effect is produced in the water. Air in direct contact with water (DEC) or indirectly in contact with the cooled water (IEC, MEC) gets cooled. The amount of water vapors that can be held by the air depend directly on its humidity ratio which is linked to the amount of moisture already present in the air. This establishes a fact that hotter the air, the better for evaporative cooling. Therefore, overheating inside the greenhouse can be avoided by natural or forced ventilation.

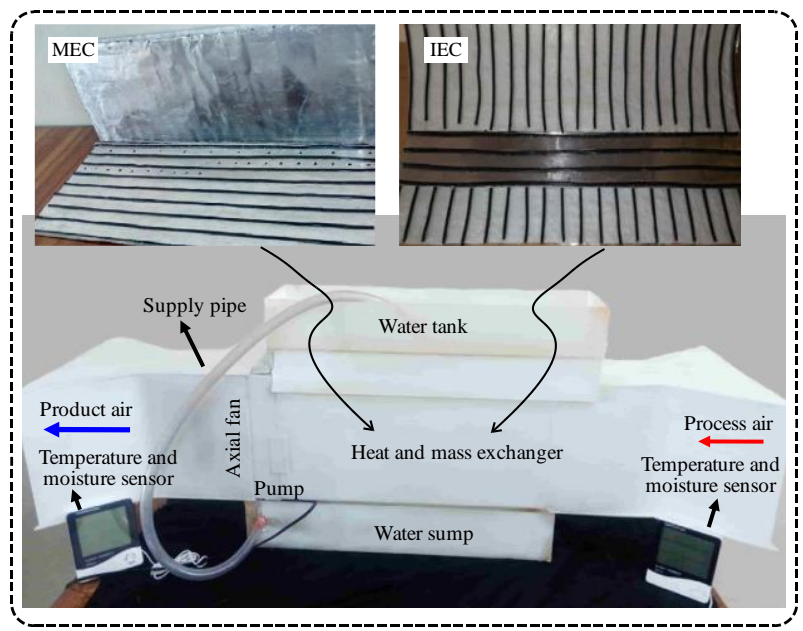

Fig. 1. Pictorial representation of developed indirect (IEC) and Maisotsenko cycle (MEC) evaporative cooling systems (a) air channels for MEC, (b) air channels for IEC, and (c) heat mass exchanger (HMX) for IEC and MEC channels.

An established fact states that 0.75 to 1 ( $75 \%$ to $100 \%)$ air renewal inside the greenhouse can eradicate additional solar heat gain [1].

Researchers have extensively studied evaporative cooling regarding various applications, greenhouse being 
one of them. El-Dessouky et al. [2] conducted an experiment of IEC coupled with DEC unit instigating two main factors of interest being material thickness and flow rate [2]. Kittas et al. [3] conducted an experimental study of a greenhouse and established main parameters impacting the design of a greenhouse i.e., ventilation rate, wind velocity, outside air temperature. Air mean temperature as well as solar radiations were measured. Results indicated that optimum temperature inside the greenhouse had a positive correlation with outside solar radiation intensity as well as ventilation rate, be it natural or forced ventilation using some equipment [3]. Teitel et al. [4] numerically computed one-dimensional models for predicting the temperature, humidity as well as carbon dioxide flux inside the greenhouse across the flow of air and compared it with experimental results. Findings showed that flux varied steeply along the mid of day due to increased solar intensity [4]. Duan et al. compiled a review of indirect evaporative cooling systems being used in different industrial sectors around the world [5]. Hasan A. provided numerical modelling of indirect evaporative cooling system and produced numerical models for performance analyses of an indirect evaporative cooling system [6].

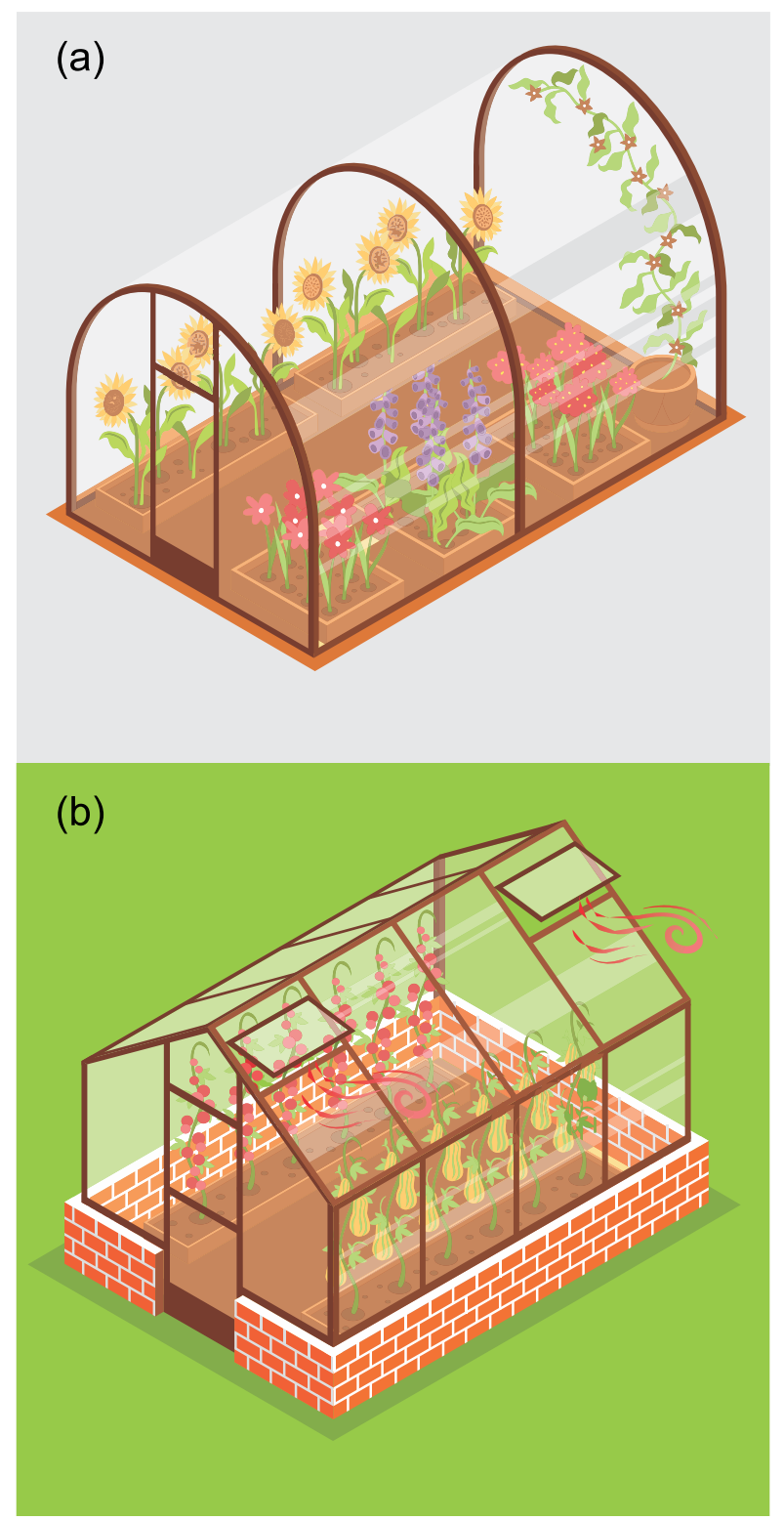

Fig. 2. Illustration of (a) conventional greenhouse and (b) naturally ventilated greenhouse.
Joudi and Hasan [7] numerically validated a solar adsorption-based IEC-DEC. Simulation results showed that inlet air temperature was $19.5{ }^{\circ} \mathrm{C}$ and outlet temperature was $48{ }^{\circ} \mathrm{C}$ in Baghdad, Iraq. Temperature inside greenhouse was $28{ }^{\circ} \mathrm{C}$ and a relative humidity level of $70 \%$ [7]. Joudi and Farhan [8] suggested an experimental solar assisted desiccant-based air evaporative air conditioner system. Results showed a decrease in solar radiation intensity inside the greenhouse which ultimately reduced the inside temperature for the climatic conditions of Baghdad, Iraq [8]. Li and Wang [9] reviewed air conditioning methods for greenhouse application. Mainly, evaporative cooling systems were highlighted in the review in viewpoints of pad, mist and roof based evaporative cooling [9]. Camelia et al. [10] studied the impact of direction of greenhouse on the performance of heating and power consumption. Results showed that E-W direction was best from power consumption point of view [10]. Emeish [11] presented the greenhouse geothermal heating for the climatic conditions of Jordan. Two study methods were used i.e., static method and energy mass balance method [11]. Ghosal and Tiwari [12] created a numerical model using geothermal energy for heating of greenhouse. Results showed that $14-23{ }^{\circ} \mathrm{C}$ rise inside the greenhouse was observed while outside air temperature was at freezing level [12]. Authors have extensively worked on the present air conditioning technology regarding several human as well as non-human applications which can be found in literature [13]-[18]. Hasan A. analyzed the effectiveness-NTU method to provide numerical model for indirect evaporative cooling system heat and mass exchanger energy transfer [19]. Costelloe et al. studied indirect evaporative cooling systems for high temperature climates around the world [20]. Zhao et al. studied experimental materials for heat and mass transfer in indirect evaporative cooling systems including metals, zeolite and fabrics [21]. The authors concluded that fiber attained metal produced the best results in terms of heat and mass transfer and purchasing cost [21]. Zhan et al. numerically studied Maisotsenko cycle evaporative cooling system and compared the results with commercially available dew point evaporative cooler (ISAW TAC-150) [22]. Heiderinejad et al. studied dual stage direct and indirect evaporative cooling systems for building application under different climatic conditions around the world. The authors concluded that $60 \%$ power saving potential could be achieved using dual stage indirect evaporative cooler and direct evaporative cooler with merely $55 \%$ increase in water consumption [23]. Delfani et al. studied the combined effect of indirect evaporative cooler coupled with mechanical vapor compression air conditioner for building air conditioning application for the climatic conditions of Iran [24].

Fig. 1 shows a pictorial representation of the developed indirect evaporative cooling (IEC) and Maisotsenko cycle evaporative cooling (MEC) systems for greenhouse air conditioning for the climatic conditions of Multan, Pakistan. Fig. 1(a) shows the air channels for Maisotsenko cycle evaporative cooling system. Fig. 1(b) shows the air channels for indirect evaporative cooling system. Fig. 1(c) shows the pictorial representation of heat mass exchanger (HMX) and temperature, relative humidity sensors at both inlet and outlet conditions. 


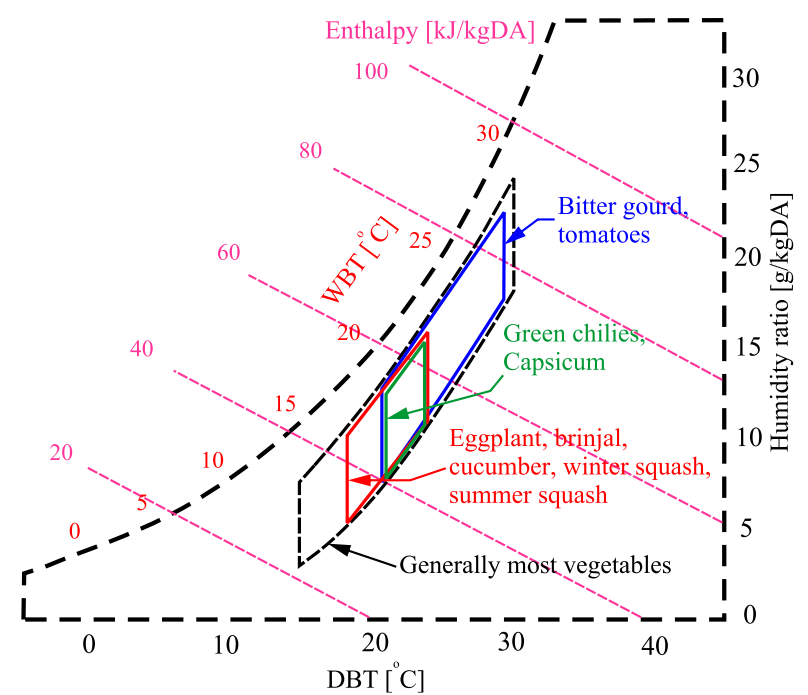

Fig. 3. Ideal growth zones of different crops in a greenhouse environment, reproduced with permission from [25].
The objective of this study is to investigate the performance of evaporative cooling-based air conditioning systems for greenhouse applications for the climatic conditions of Multan, Pakistan. The desired design parameters for greenhouse application in general (excluding vapor pressure deficit) are inside dry-bulb temperature $\left({ }^{\circ} \mathrm{C}\right)$ and relative humidity level $(\%)$ of air inside green house. Optimum growth for plants is necessary to maintain an optimum yield production. The proposed evaporative cooling-based air conditioning system has been illustrated in Fig. 3 with cool air being blown into the greenhouse and warm air being released from the greenhouse producing a forced ventilation as well as nullifying the overheating effect of solar radiation intensity in an enclosed space (greenhouse).

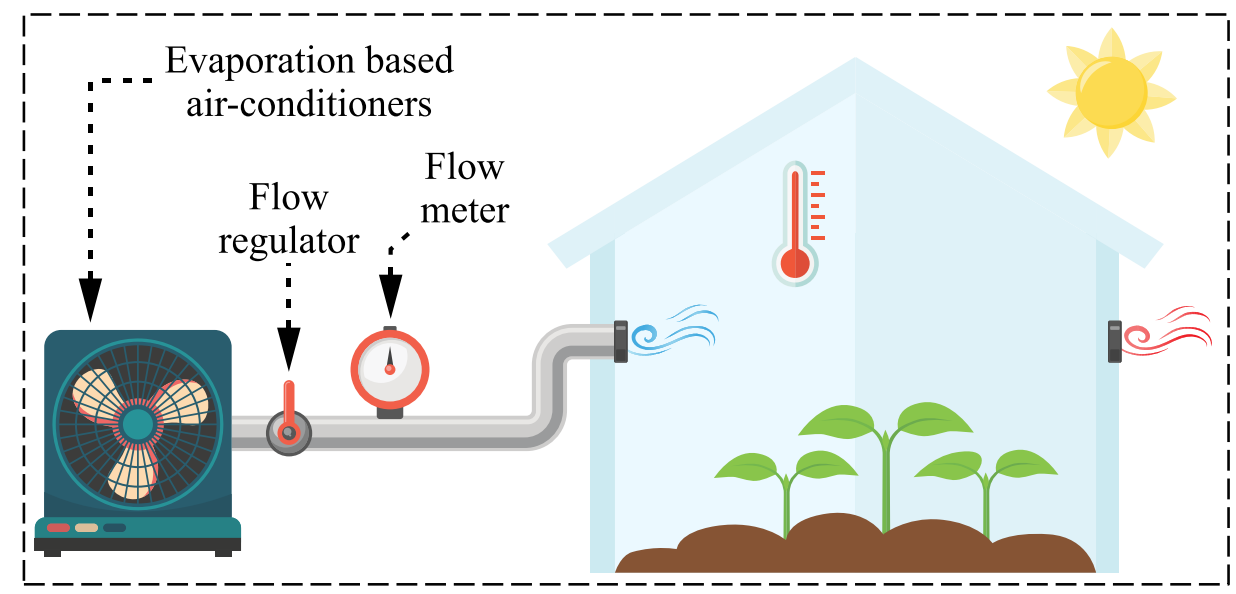

Fig. 4. Proposed evaporative cooling-based air conditioning system for greenhouses.

\section{METHODOLOGY}

\subsection{System specifications and design conditions}

Climatic data and system outlet data for the present study was obtained from DEC, IEC and MEC experimental systems installed at Department of Agricultural Engineering, Bahauddin Zakariya University, Multan. Effective area of experimental systems both IEC and MEC systems was $0.1032 \mathrm{~m}^{2}$ and $0.0871 \mathrm{~m}^{2}$ for DEC. System was designed to achieve certain thermal and humidity comfort zone levels which are recommended for optimum greenhouse conditions in literature. Fig. 2 represents some crops' optimum thermal comfort zones inside the greenhouse environment. A general ideal growth zone for different crops in greenhouse is also marked in Fig. 2.

\subsection{Experimental uncertainty}

$$
\sigma \varepsilon_{w b}= \pm \sqrt{\left(\frac{\delta \varepsilon_{w b}}{\delta D B T_{s y s}} \cdot \sigma D B T_{s y s}\right)^{2}+\left(\frac{\delta \varepsilon_{w b}}{\delta W B T} \cdot \sigma W B T\right)^{2}}
$$

$$
\sigma \varepsilon_{d p}= \pm \sqrt{\left(\frac{\delta \varepsilon_{d p}}{\delta D B T_{s y s}} \cdot \sigma D B T_{s y s}\right)^{2}+\left(\frac{\delta \varepsilon_{d p}}{\delta D P T} \cdot \sigma T_{d p t}\right)^{2}}
$$

where, $\sigma \varepsilon_{w b}$ represents uncertainty in the wet bulb effectiveness of the experiment and $\sigma \varepsilon_{d p}$ represents the uncertainty in the dewpoint effectiveness (correlating with dewpoint temperature of the working air (DPT)) of the experiment. $\sigma D B T_{\text {sys }}, \sigma W B T$ are the fixed measuring instrument uncertainties $\left( \pm 1{ }^{\circ} \mathrm{C}\right)$. Total experimental uncertainty $\sigma \varepsilon_{w b}$ in MEC, DEC \& IEC systems is \pm 0.09 , \pm 0.08 and \pm 0.09 , respectively. $\sigma \varepsilon_{d p}$ is \pm 0.14 in MEC.

\subsection{System performance analysis}

$$
\varepsilon_{\text {dewpoint }}=\frac{T_{\text {inlet }}-T_{\text {sys }}}{T_{\text {inlet }}-D P T}
$$




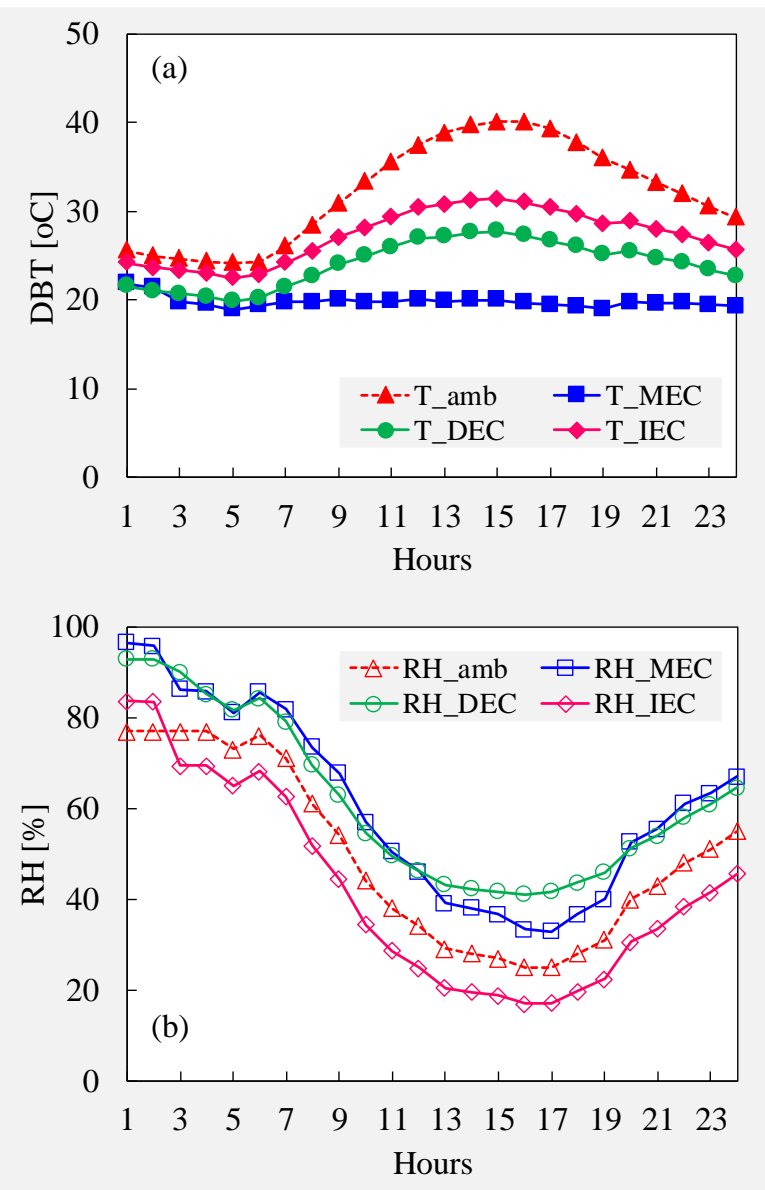

Fig. 5. Profile of temperature and relative humidity of MEC, DEC, IEC systems \& ambient conditions of Multan.

$$
\varepsilon_{\text {wetbulb }}=\frac{T_{\text {in }}-T_{\text {out }}}{T_{\text {in }}-W B T}
$$

where $\varepsilon_{\text {dewpoint }}$ is the effectiveness of the dewpoint evaporative air conditioner (M-cycle evaporative cooler), $\varepsilon_{\text {wetbulb }}$ is the efficiency of wet bulb evaporative air conditioner (DEC \& IEC), $T_{\text {inlet }}$ and $T_{\text {sys }}$ represent inlet ambient air temperature in ${ }^{\circ} \mathrm{C}$ and supply air temperature at the outlet of each system in ${ }^{\circ} \mathrm{C}$, respectively. $D P T$ and $W B T$ show ambient air dewpoint temperature and wet bulb temperature in ${ }^{\circ} \mathrm{C}$, respectively.

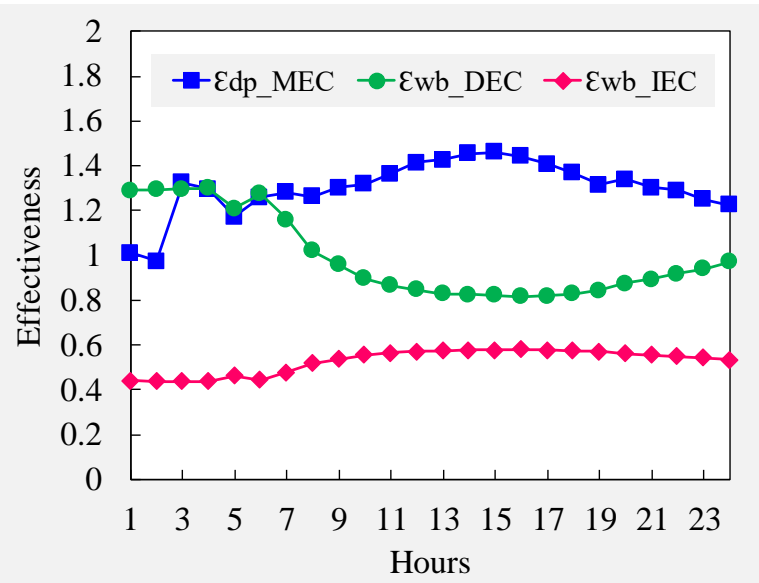

Fig. 6. Effectiveness profile of MEC, DEC and IEC systems.

\section{RESULTS AND DISCUSSION}

Profile of the experimental results obtained from the DEC, MEC, and IEC systems on May 15 ${ }^{\text {th }}, 2018$ are represented in Fig. 4. Fig. 4(a) represents temperature profile of all three evaporative cooling systems compared to ambient dry bulb temperature conditions of 24 hours. Fig. 4(b) represents the respective relative humidity profile. Maximum temperature gradient comparative to outside dry bulb temperature was observed in case of MEC i.e., $20.35{ }^{\circ} \mathrm{C}$. DEC produced a moderate temperature gradient of $12.78{ }^{\circ} \mathrm{C}$. Whereas, IEC could reach the least maximum temperature gradient of $9.05^{\circ} \mathrm{C}$ throughout the day. In case of relative humidity, MEC increased the supply air relative humidity to a maximum of $19.47 \%$ throughout the day, $16.61 \%$ in case of DEC system and $6.62 \%$ maximum increase in case of IEC system.

Fig. 6 shows the temperature and relative humidity conditions of all three evaporative cooling systems compared to ambient air conditions in viewpoint of general optimum zone for most of the crops grown in greenhouse. Evidently, MEC behaved in a best manner to meet the set design conditions of optimum greenhouse growth zone, most of the supply air conditions falling within the zone. The DEC system behaved moderately to achieve the set point temperature and relative humidity conditions whereas most of the IEC readings did not meet the required optimum growth zone represented on psychrometric chart in Fig. 6.

System performance in terms of dewpoint effectiveness $\left(\varepsilon_{\text {DPT }}\right)$ and wet bulb effectiveness $\left(\varepsilon_{\mathrm{WBT}}\right)$ was also evaluated for the climatic conditions of Multan, Pakistan for May $15^{\text {th }}$, 2018. Fig. 5 represents the $\varepsilon_{\mathrm{WBT}}$ of the DEC and IEC systems, while $\varepsilon_{\text {DPT }}$ in case of the MEC system. The MEC system performed admirably throughout the day whereas the DEC system performed moderately, and the IEC system was found to be the least effective evaporative cooling system for greenhouse air conditioning application.

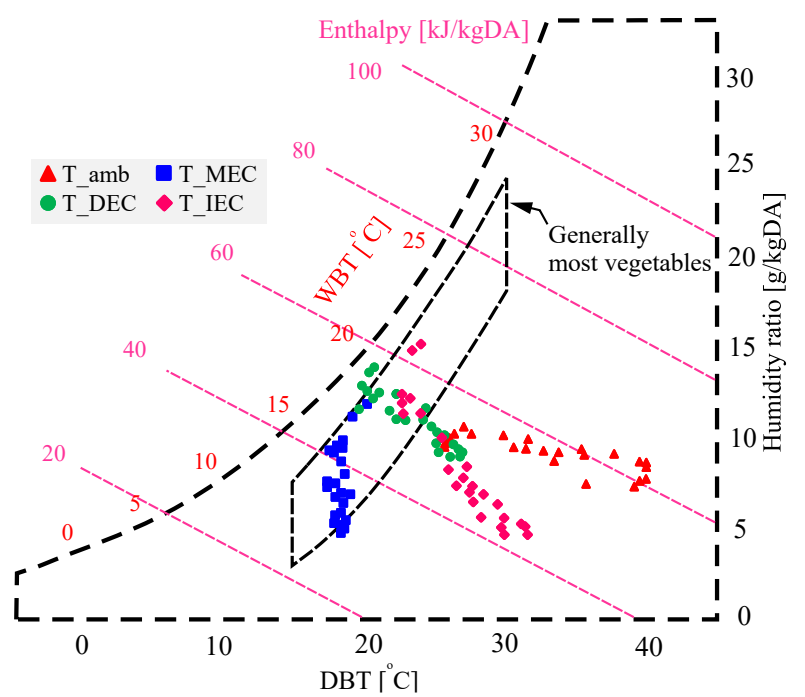

Fig. 7. Psychrometric representation of thermodynamic performance of the DEC, IEC \& MEC systems on $15^{\text {th }}$ May for the climatic conditions of Multan (Pakistan). 


\section{CONCLUSIONS}

In the present study, three types of evaporative cooling systems were designed and tested for greenhouse air conditioning of different crops. Evaporative cooling option was found to be an effective alternative compared to vapor compression systems. Key findings drawn from the present study are:

- Maisotsenko cycle based evaporative cooling (MEC) was found to be the most effectiveness option to achieve set optimum growth zone in a greenhouse environment.

- MEC system created a dry bulb temperature flux of $20.35{ }^{\circ} \mathrm{C}$ compared to outside air conditions.

- Performance of any evaporative cooling system mainly depended on the inlet ambient air psychrometric conditions.

\section{Acknowledgements}

All this work is part of the Ph.D. research of Ms. Shazia Noor ( $1^{\text {st }}$ Author). This research work has been carried out in the Department of Agricultural Engineering, Bahauddin Zakariya University, Multan-Pakistan. This research was funded by Bahauddin Zakariya University, Multan-Pakistan under the Director Research/ ORIC grant titled "Development and performance evaluation of prototypes of direct and indirect evaporative coolingbased air-conditioning systems" awarded to Principal Investigator: Dr. Muhammad Sultan.

\section{Conflict of interest}

The authors declare no conflict of interest.

\section{REFERENCES}

[1] ASHRAE, Handbook-HVAC Applications SI. 2019.

[2] H. El-Dessouky, H. Ettouney, and A. AlZeefari, "Performance analysis of two-stage evaporative coolers," Chemical Engineering Journal, vol. 102, no. 3, pp. 255-266, 2004, doi: 10.1016/j.cej.2004.01.036.

[3] C. Kittas, M. Karamanis, and N. Katsoulas, “Air temperature regime in a forced ventilated greenhouse with rose crop," Energy and Buildings, vol. 37, no. 8, pp. 807-812, 2005, doi: 10.1016/j.enbuild.2004.10.009.

[4] M. Teitel, M. Atias, and M. Barak, "Gradients of temperature, humidity and $\mathrm{CO} 2$ along a fanventilated greenhouse," Biosystems

Engineering, vol. 106, no. 2, pp. 166-174, 2010, doi: 10.1016/j.biosystemseng.2010.03.007.

[5] Z. Duan, C. Zhan, X. Zhang, M. Mustafa, X. Zhao, B. Alimohammadisagvand, and A. Hasan, "Indirect evaporative cooling: Past, present and future potentials," Renewable and Sustainable Energy Reviews, vol. 16, no. 9, pp. 6823-6850, 2012, doi: 10.1016/j.rser.2012.07.007.

[6] A. Hasan, "Indirect evaporative cooling of air to a sub-wet bulb temperature," Applied Thermal Engineering, vol. 30, no. 16, pp. 2460-2468, 2010, doi: 10.1016/j.applthermaleng.2010.06.017.

[7] K. Ahmed, J. Mustafa, and M. Hasan, "Cooling and Heating a Greenhouse in Baghdad by a
Solar Assisted Desiccant System," Journal of Engineering, vol. 19, no. 8, pp. 933-951, 2013.

[8] K. A. Joudi and A. A. Farhan, "Greenhouse heating by solar air heaters on the roof," Renewable Energy, vol. 72, pp. 406-414, 2014, doi: 10.1016/j.renene.2014.07.025.

[9] H. Li and S. Wang, "Technology and Studies for Greenhouse Cooling," World Journal of Engineering and Technology, vol. 03, no. 03, pp. 73-77, 2015, doi: 10.4236/wjet.2015.33b012.

[10] C. Stanciu, D. Stanciu, and A. Dobrovicescu, "Effect of Greenhouse Orientation with Respect to E-W Axis on its Required Heating and Cooling Loads," Energy Procedia, vol. 85, pp. 498-504, 2016, doi: 10.1016/j.egypro.2015.12.234.

[11] M. S. Emeish and R. S. Society, Geothermal Heating System for, no. 2. United Nations University, 1999.

[12] M. K. Ghosal and G. N. Tiwari, "Mathematical modeling for greenhouse heating by using thermal curtain and geothermal energy," Solar Energy, vol. 76, no. 5, pp. 603-613, 2004, doi: 10.1016/j.solener.2003.12.004.

[13] H. Niaz, M. Sultan, T. Miyazaki, and Z. M. Khan, "Study on Desiccant Air-Conditioning System for Livestock Application in Pakistan," ICECE 2018 - 2018 2nd International Conference on Energy Conservation and Efficiency, Proceedings, pp. 19-22, 2018, doi: 10.1109/ECE.2018.8554983.

[14] M. Sultan, T. Miyazaki, M. H. Mahmood, and Z. M. Khan, "Solar assisted evaporative cooling based passive air-conditioning system for agricultural and livestock applications," Journal of Engineering Science and Technology, vol. 13, no. 3, pp. 693-703, Mar. 2018.

[15] M. H. Mahmood, M. Sultan, T. Miyazaki, S. Koyama, and V. S. Maisotsenko, "Overview of the Maisotsenko cycle - A way towards dew point evaporative cooling," Renewable and Sustainable Energy Reviews, vol. 66, pp. 537555, 2016, doi: 10.1016/j.rser.2016.08.022.

[16] M. H. Mahmood, M. Sultan, and T. Miyazaki, "Experimental evaluation of desiccant dehumidification and air-conditioning system for energy-efficient storage of dried fruits," Building Services Engineering Research and Technology, p. 0143624419893660, Dec. 2019, doi: 10.1177/0143624419893660.

[17] S. Hanif, M. Sultan, T. Miyazaki, and S. Koyama, "Effect of drying air parameters on energy consumption in desiccant grain drying," in Proceedings of International Exchange and Innovation Conference on Engineering \& Sciences (IEICES), 2017.

[18] M. H. Mahmood, M. Sultan, T. Miyazaki, and S. Koyama, "Study on desiccant airconditioning system for agricultural product storage in Pakistan," in Proceedings of International Exchange and Innovation Conference on Engineering \& Sciences (IEICES), 2015, no. 1, p. 1.

[19] A. Hasan, "Going below the wet-bulb 
temperature by indirect evaporative cooling: Analysis using a modified $\varepsilon$-NTU method," Applied Energy, vol. 89, no. 1, pp. 237-245, 2012, doi: 10.1016/j.apenergy.2011.07.005.

[20] B. Costelloe and D. Finn, "Indirect evaporative cooling potential in air-water systems in temperate climates," Energy and Buildings, vol. 35, no. 6, pp. 573-591, 2003, doi: 10.1016/S0378-7788(02)00161-5

[21] X. Zhao, S. Liu, and S. B. Riffat, "Comparative study of heat and mass exchanging materials for indirect evaporative cooling systems," Building and Environment, vol. 43, no. 11, pp. 19021911, 2008, doi:

10.1016/j.buildenv.2007.11.009.

[22] C. Zhan, Z. Duan, X. Zhao, S. Smith, H. Jin, and S. Riffat, "Comparative study of the performance of the M-cycle counter-flow and cross-flow heat exchangers for indirect evaporative cooling - Paving the path toward sustainable cooling of buildings," Energy, vol. 36, no. 12, pp. 6790-6805, 2011, doi: https://doi.org/10.1016/j.energy.2011.10.019.

[23] G. Heidarinejad, M. Bozorgmehr, S. Delfani, and J. Esmaeelian, "Experimental investigation of two-stage indirect/direct evaporative cooling system in various climatic conditions," Building and Environment, vol. 44, no. 10, pp. 20732079, 2009, doi:

10.1016/j.buildenv.2009.02.017.

[24] S. Delfani, J. Esmaeelian, H. Pasdarshahri, and M. Karami, "Energy saving potential of an indirect evaporative cooler as a pre-cooling unit for mechanical cooling systems in Iran," Energy and Buildings, vol. 42, no. 11, pp. 2169-2176, 2010, doi: 10.1016/j.enbuild.2010.07.009.

[25] M. Sultan and T. Miyazaki, "Energy-Efficient Air-Conditioning Systems for Nonhuman Applications," in Refrigeration, O. Ekren, Ed. InTech, 2017. 